\title{
The Teacher Academic Buoyancy Scale: Is it possible to keep TABS on students' academic buoyancy?
}

\author{
Diarmuid Verrier (iD 1,*, Scott Johnson ${ }^{1}$, Lisa Reidy (i) 1 \\ ${ }^{1}$ Department of Psychology, Sociology, and Politics, Sheffield Hallam University, Sheffield, S10 2BQ, UK
}

\section{ARTICLE HISTORY}

Received: 29 June 2018

Revised: 13 September 2018

Accepted: 24 September 2018

\section{KEYWORDS}

Academic,

Buoyancy,

Resilience,

Teachers,

Scale

\begin{abstract}
Academic buoyancy (AB) is the ability to overcome minor academic setbacks. However, although it seems as though teachers would be well placed to comment on this characteristic in students, no teacherreport measure of $\mathrm{AB}$ exists. This study evaluates a teacher-report version of the widely used, student-report, Academic Buoyancy Scale (ABS). Confirmatory factor analysis supported the unifactorial nature of the Teacher Academic Buoyancy Scale (TABS), and the scale showed excellent internal reliability. However, while there was some evidence for the criterion-related validity of the TABS, it showed very poor convergent validity with the $\mathrm{ABS}$. It also correlated better with academic achievement than should theoretically be the case for a measure of AB. Further, AB estimates from the two measures were moderated by demographic characteristics: teachers rated girls and those not facing adversity as more buoyant, but the opposite was the case for self-reports. In sum, this study suggests a significant disjunction between teacher- and self-reports of $\mathrm{AB}$, and that teacher estimates of $\mathrm{AB}$ are likely to be affected by salient, nonAB-related, student characteristics.
\end{abstract}

\section{INTRODUCTION}

Resilience is defined as the ability to overcome adversity through adaptation (Howard \& Johnson, 2000) and has clear implications for achievement and coping within an individual's life (Drapeau, Saint-Jacques, Lépine, Bégin \& Bernard, 2007). Resilience considered in an academic context has led to the exposition of two fundamental constructs: academic buoyancy (AB) and academic resilience (AR; Martin, 2013). Both AR and AB are relevant to the ability of individuals to overcome setbacks that have the potential to limit motivation and performance (Martin \& Marsh, 2008a). However, they are ontologically distinct in terms of their kind and degree, relevance to different populations (Martin \& Marsh, 2008a), and relevance to academic outcomes (Martin, 2013). Specifically, AB applies to the majority of individuals in an academic setting whereas AR applies to individuals who may experience acute adversity (e.g. major illness or emotional/behavioural difficulties; Martin \& Marsh, 2009). Poor AB is related to lowlevel negative outcomes such as achievement anxiety, isolated poor grades, temporary lapses in engagement and motivation, and minor negative interactions with teachers; poor AR is

CONTACT: Diarmuid Verrier $₫$ d.verrier@shu.ac.uk 프 Department of Psychology, Sociology, and Politics, Sheffield Hallam University, Sheffield, S10 2BQ, UK 
predictive of high-level negative outcomes such as disengagement from school, chronic under achievement, sustained disaffection and truancy, and opposition to teachers (Martin, 2013). On the other hand, high levels of $\mathrm{AB}$ have been found to correlate well with attendance, engagement in lessons, positive regard for school, persistence, planning, confidence, and academic achievement (Martin, Colmar, Davey, \& Marsh, 2010; Martin \& Marsh, 2006; Martin, 2014b). Putwain and Daly (2013) looked at the effect of AB and test anxiety on performance on the General Certificate of Secondary Education (GCSE) in the UK. Test scores were shown to be best when academic buoyancy was high and test anxiety was low to medium. A number of student characteristics show very small associations with buoyancy. For example, being female, facing adversity, and being from a lower socio-economic background all predict lower buoyancy (Martin, 2013)

Despite its potential importance, academic buoyancy remains an understudied construct with most of the research done by a relatively small group of scholars. Further, there is a repeated concern throughout the $\mathrm{AB}$ literature that all data so far has been generated solely via self-report measures (Malmberg, Hall, \& Martin, 2013; Martin, 2013; Martin et al., 2010). Bernard, Killworth, Kronenfeld and Sailor (1984) suggested that on average almost half of self-report responses may be inaccurate, while Fan et al. (2006) highlighted deliberately misleading answers from adolescent participants as a concern. The combined impact of these problems on validity means that $A B$ research is in need of an alternative means of assessment. Given AB's academic context and the responsibility of teachers to monitor students, a student measure that could be completed by teachers would be appropriate.

However, while teachers are quite good at accurately predicting students' academic achievement (Sudkamp, Kaiser, \& Moller, 2012), evidence for the validity of their assessments of students' internal, affective and motivational, states has been less impressive. In general, findings in this area have shown the association between teacher- and self-ratings to be low to moderate. For example, a meta-analysis by Renk and Phares (2004) found the average correlation between teacher- and self-ratings of social competence to be around .25 , while a more recent study by Zhu and Urhahnes (2014) found a strong association for academic selfconcept, a moderate one for learning effort and enjoyment, and no association at all for test anxiety. Teachers' ratings are likely to be affected by student characteristics (Meissel, Meyer, Yao, \& Rubie-Davies, 2017) as well as their own characteristics and the school environment (Pas \& Bradshaw, 2014).

Of course, the availability of relevant information is also essential for any evaluation of personality (Funder, 2012). As an observer-report instrument, a scale designed to be completed by a teacher would need to be linked to observable behaviours. Martin (2002), drawing on a number of theoretical perspectives, characterised resilient (buoyant) students as demonstrating optimism, proactivity, persistence, attention, effort, and a sense of control over academic outcomes; they do not show anxiety, self-doubt, procrastination, or disengagement. As all of these manifest behaviourally in the classroom, to a greater or lesser degree, a teacher-report measure does seem practical. As there already exists a well-used measure of AB (the Academic Buoyancy Scale; Martin \& Marsh, 2008a), the current study used a reworded version of this measure.

The current research has two key aims. The first aim is the psychometric evaluation of this new teacher-report measure of AB -- the Teacher Academic Buoyancy Scale (TABS). Concurrent validity will be assessed via its correlation with the Academic Buoyancy Scale (Martin \& Marsh, 2008a), the high school version of the Motivation and Engagement Scale (Martin, 2007), and (prior) academic achievement. The second aim is to investigate which factors might differentially predict teacher-ratings and self-ratings of AB. 


\section{METHOD}

\subsection{Participants}

Participants were students and staff at an Academy in the north of England. The students were in the penultimate year (Year 10) of their GCSEs. There were 108 students ( 56 female; 5 from an ethnic minority group) with a mean age of 14.71 years. Each student's buoyancy was rated by one teacher who was familiar with the student. In total, 50 teachers representing 11 subjects acted as a rater. Each teacher rated at most four students. Eight participants failed to complete at least one entire scales' worth of data and were removed leaving 100 students participants, 24 of whom were identified as facing some form of acute adversity (behavioural difficulty, attendance issues, major illness, or special educational needs).

\subsection{Measures}

\subsubsection{Academic Buoyancy Scale}

Academic buoyancy was measured using the 4-item self-report Academic Buoyancy Scale (ABS; Martin \& Marsh, 2008a), which uses a 7-point Likert scale. This has previously demonstrated excellent test re-test reliability (Martin et al., 2010), and internal consistency (Martin \& Marsh, 2008b). Items assess student ability to bounce back from adversity (e.g. "I don't let a bad mark affect my confidence"). In the present study, Cronbach's $\alpha$ was .82 .

\subsubsection{Motivation and Engagement Scale - High School (MES-HS)}

The 44-item MES-HS (Martin, 2014a) is a self-report instrument that assesses 11 motivation and engagement factors in students (see Table 2). It uses a 7-point Likert scale. Previous research has demonstrated good reliability and internal consistency (Martin, 2007).

\subsubsection{Academic Achievement}

End of Key Stage 2 and 3 results in English and Maths were used as markers of academic performance. End of Key Stage 2 (KS2) national tests provide standardised results for students at the age of 10-11. End of Key Stage 3 (KS3) results come from tests performed within the school at the age of 12-13. They are not nationally standardised but are internally moderated to check for consistency.

\subsubsection{Teacher Academic Buoyancy Scale}

The TABS measure consists of the four items from the ABS reworded to refer to the student in the third person (e.g., "The student doesn't let a bad mark affect their confidence"). A teacher who knows the student well can use it to rate the student's level of academic buoyancy. It uses a 7-point Likert scale ( $1=$ "Strongly disagree" to $7=$ "Strongly agree"). Given that the ABS already has an established unifactorial structure, confirmatory factor analysis (CFA) was used to assess whether the TABS was also unifactorial. The maximum likelihood CFA was done in jamovi (jamovi project, 2018) and the model was generally supported. The chi-square value was not significant; the CFI was .98; the TLI was .95; and the SRMR had a value of .03. The only index of fit that did not support the model was the RMSEA, which was .13 (90\%CI: .00 .26). However, this statistic has been shown to frequently reject true models given a low sample size ( $\mathrm{N} \leq 250 ; \mathrm{Hu} \&$ Bentler, 1999). Intercorrelations between the four items can be seen in Table 1. The internal reliability of this four-item scale was excellent (Cronbach's $\alpha=.84$ ). 
Table 1. Intercorrelations between items on the Teacher Academic Buoyancy Scale $(N=100)$

\begin{tabular}{lcccc} 
& Mean (SD) & \multicolumn{3}{c}{ Correlations } \\
\cline { 3 - 5 } Item & & 2 & 3 & 4 \\
\hline $\begin{array}{l}\text { 1. The student does not let stress get on } \\
\text { top of them }\end{array}$ & $4.33(1.48)$ & .44 & .72 & .70 \\
$\begin{array}{l}\text { 2. The student is good at dealing with } \\
\text { schoolwork pressures }\end{array}$ & $4.98(1.29)$ & & .45 & .54 \\
3. The student does not let a bad mark & $4.50(1.25)$ & & .63 \\
affect their confidence & & & \\
4. The student is good at dealing with \\
setbacks (e.g. negative feedback on \\
their work, poor results)
\end{tabular}

Note: $\mathrm{p}<.001$ for all correlations.

\section{RESULTS}

\subsection{Criterion-related validity}

Prior to analysis, item scores were reversed where appropriate and summed to provide total scores for each scale and subscale. Four subscales from the MES-HS had skew values that exceeded twice the standard error of skew. A square root transform was sufficient to appropriately reduce this before further analysis.

Table 2. Descriptive Statistics and Correlations between the Academic Buoyancy and Criterion Variables $(N=100)$

\begin{tabular}{|c|c|c|c|c|c|c|c|}
\hline & \multirow[b]{2}{*}{$\begin{array}{l}\text { Mean } \\
\text { (SD) }\end{array}$} & \multicolumn{2}{|c|}{ Correlations } & & \multirow[b]{2}{*}{$\begin{array}{l}\text { Mean } \\
\text { (SD) }\end{array}$} & \multicolumn{2}{|c|}{ Correlations } \\
\hline & & TABS & ABS & & & TABS & ABS \\
\hline Academic & & & & MES-HS & & & \\
\hline Buoyancy & & & & & & & \\
\hline TABS & $\begin{array}{l}18.49 \\
(4.46)\end{array}$ & - & - & Self-belief & $\begin{array}{c}74.11 \\
(15.95)\end{array}$ & .13 & $.30 * *$ \\
\hline $\mathrm{ABS}$ & $\begin{array}{l}17.09 \\
(4.93)\end{array}$ & -.02 & - & Valuing & $\begin{array}{c}73.70 \\
(14.90)\end{array}$ & .05 & $.26^{* *}$ \\
\hline $\begin{array}{l}\text { Academic } \\
\text { Achievement }\end{array}$ & & & & Learning Focus & $\begin{array}{c}75.36 \\
(14.39)\end{array}$ & .01 & .19 \\
\hline Key Stage 2 & $\begin{array}{c}4.28 \\
(0.51)\end{array}$ & $.32 *$ & $-.22 *$ & Planning & $\begin{array}{l}56.90 \\
(20.76)\end{array}$ & .14 & .18 \\
\hline Key Stage 3 & $\begin{array}{c}6.29 \\
(0.78)\end{array}$ & $.40 * *$ & $-.24 *$ & Task Management & $\begin{array}{c}68.04 \\
(19.97)\end{array}$ & $.21 *$ & .11 \\
\hline Progress & $\begin{array}{c}2.03 \\
(0.44)\end{array}$ & $.30^{*}$ & -.12 & Persistence & $\begin{array}{c}63.34 \\
(16.79)\end{array}$ & .06 & .13 \\
\hline & & & & Anxiety & $\begin{array}{c}67.11 \\
(19.96)\end{array}$ & .13 & $-.45^{* *}$ \\
\hline & & & & Failure Avoidance & $\begin{array}{c}51.14 \\
(20.11)\end{array}$ & .01 & -.16 \\
\hline & & & & Uncertain Control & $\begin{array}{c}53.14 \\
(16.13)\end{array}$ & -.09 & -.12 \\
\hline & & & & Self-Sabotage & $\begin{array}{c}39.61 \\
(18.58)\end{array}$ & -.16 & $-.21 *$ \\
\hline & & & & Disengagement & $\begin{array}{c}41.64 \\
(19.95) \\
\end{array}$ & -.16 & $-.34 *$ \\
\hline
\end{tabular}

$* \mathrm{p}<.05 * * \mathrm{p}<.001$ 
Notably, there was no association between the teacher and student ratings of student academic buoyancy, suggesting poor convergent validity. Evidence for concurrent validity was assessed through correlations between AB measures and the MES-HS subscales (see Table 2). With regards to the MES-HS subscales, the TABS showed a weak positive correlation with task management. No other correlations were significant (though there did appear to be weak effects that were generally in the expected direction). The ABS also correlated in the expected direction with a number of MES-HS subscales.

$\mathrm{AB}$ has been shown to have a weak positive association with academic achievement in certain contexts. Here, the ABS correlated negatively with (prior) academic performance, though these were, predictably, weak effects (see Table 2). In contrast, the TABS showed moderate positive associations with students' KS2 and KS3 results and their academic progress (difference between KS2 and KS3 results).

\subsection{Moderators of $A B$ rating}

We investigated whether the estimates of buoyancy provided by the TABS and ABS were dependent on group membership. An inverse pattern was observed when comparing boys and girls using the two measures (see Fig. 1a). Boys rated themselves as more buoyant, $t(98)=$ $3.25, p=.002, d=.66$; however, they were rated by teachers as less buoyant, albeit not significantly so, $t(98)=1.06, p=.290, d=.21$.

A similar pattern was seen when comparing students who were identified as facing particular adversity with those who were not (see Fig. 1b). Adversity-facing students rated themselves as more buoyant, $t(98)=2.17, p=.032, d=.54$, but were rated as less buoyant by teachers, $t(98)$ $=4.25, p<.001, d=1.04$. The interactions suggested by these two patterns of results (i.e., gender/adversity $\times \mathrm{AB}$ measure) were found to be significant when tested via $2 \times 2$ ANOVAs (gender interaction: $\eta_{\mathrm{p}}^{2}=.09$; adversity interaction: $\eta_{\mathrm{p}}^{2}=.18$ ).

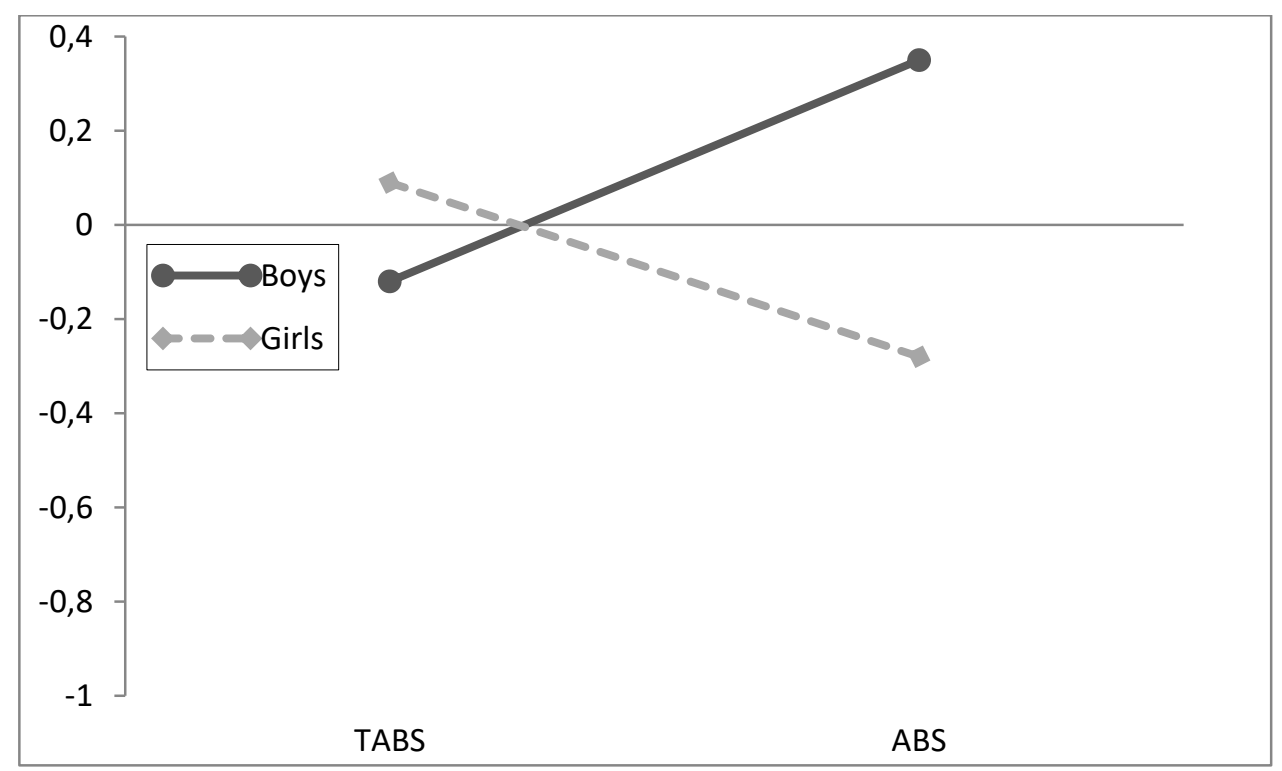

Figure 1a. Group differences in teacher-rated (TABS) and self-rated (ABS) academic buoyancy between boys and girls (standardised scores). 


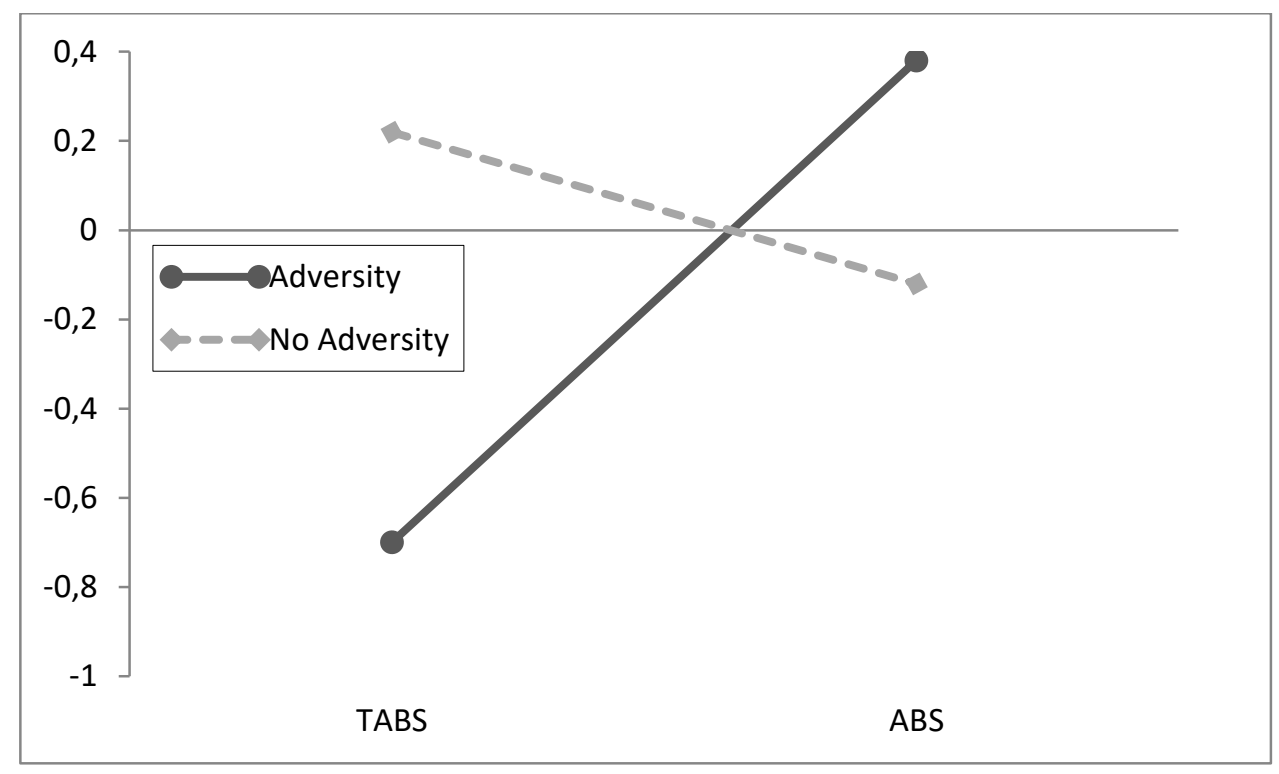

Figure 1b. Group differences in teacher-rated (TABS) and self-rated (ABS) academic buoyancy between those facing/not-facing adversity (standardised scores).

\section{DISCUSSION}

This study used a reworded version of the ABS to create a teacher-report measure of academic buoyancy. After confirming that the TABS shows the same unifactorial structure as the ABS, the psychometric properties of the scale were evaluated. The TABS had excellent internal consistency, but showed poor validity in a number of respects. In terms of convergent validity, one would expect a teacher-report of a student's academic buoyancy to correlate with the student's self-report, especially when the wording of the two scales differ so slightly. However, there was absolutely no association between the two scores. Concurrent validity was assessed in two ways: through the TABS' correlation with student motivation and engagement and through its association with prior academic achievement. Correlations between the TABS and the subscales of the MES-HS were uniformly weak, with only one (the association with task management) being significant. Conversely, the ABS showed moderate associations with several of the MES-HS subscales, and all correlations were in the expected direction (Martin, 2007, 2013). AB has been shown, at best, to be a weak predictor of attainment/achievement (Martin, 2014b) and any effect it has is likely to be indirect, through, for example, an enhanced sense of control (Collie et al., 2015). As such, one would expect a valid measure of AB to only weakly correlate with academic achievement. While this was the case for the ABS, there were moderate positive associations between the TABS and academic achievement. Thus, in terms of both convergent and concurrent validity, the TABS seems wanting.

In order to discern whether student characteristics might predict teacher bias (or, indeed, student bias), we also investigated the degree to which gender and facing adversity moderated estimates of AB. Adversity was defined broadly as having experienced behavioural difficulties, attendance issues, or major illness; or as having special educational needs. We found, in keeping with previous data (Martin, 2013) that women reported themselves as less buoyant than men. However, the opposite was the case for teacher reports, where women were perceived as being more buoyant. A similar effect was observed for adversity, where those facing adversity rated themselves as more buoyant (an unexpected finding), while being rated as less buoyant by teachers. 
A prerequisite for accurate judgements of personality traits is that relevant behavioural information must be available and detected by the judge (Funder, 2012). The poor association between teacher reports of $\mathrm{AB}$ and self-reports of largely psychological states (buoyancy, motivation, and engagement) may suggest that the information teachers would need to make a valid estimate of $A B$ is lacking, or less salient than it could be. In the absence of such information, teachers are likely to rely on more salient, non-AB-related, student characteristics. These could include academic performance, gender, and known adversity. Relying on academic performance as a guide would explain the observed, theoretically unexpected, association between this and TABS scores. Similarly, while women have been shown to report themselves as having lower AB than men do (Martin, 2013), they are seen by teachers to be "good" students: more verbally capable, conscientious, and engaged (e.g., Åhslund \& Boström, 2018). Adversity, as defined here, included behavioural difficulties, which has been shown to be associated with unrealistically low judgements of academic performance (Bennet, Gottesman, Rock, Cerullo, \& Levin, 1993). The same process may be at work here in teacher judgements of $\mathrm{AB}$. This fundamental problem is likely to be endemic to any attempt to get an accurate observer-report measure of AB. Ensuring that the rater is blind to the student's past academic performance and behavioural history means that they will equally be blind to behaviours that would be relevant to $\mathrm{AB}$.

While the present study suggests that it may not be possible to satisfactorily convert the ABS directly into a teacher-report measure of $\mathrm{AB}$, the need for a teacher- or parent-report $\mathrm{AB}$ scale persists. Apart from the triangulationary value provided by such a measure alongside a selfreport measure, it could actually be more accurate than self-report. For example, when Skinner, Kinderman, \& Furrer (2009) looked at student self-report engagement scores, teacher-assessed engagement scores, and in vivo observations of engagement behaviours, the teacher scores were found to correlate better with observed engagement behaviour than self-report. It may be necessary to create such a scale entirely from scratch, paying particular attention to the space in which $\mathrm{AB}$ and observable behaviour overlap. Adding guidelines to the scale that can help the rater to disregard academic performance and other salient non-AB-related behaviours may also be of use.

Future research into the creation and validation of a teacher-report scale should use larger samples and evaluate its performance in different academic contexts. Looking at the relative predictive power of self-report and teacher-report measures of $A B$ would help to ascertain whether one is strictly more valuable or whether they should be used alongside one another. To that end, the inclusion of additional criterion variables in future research would also be recommended. For example, the new subscale could be correlated against in vivo ratings of students' buoyant behaviours made by an independent observer.

In conclusion, although there is an apparent need for a teacher-report measure of $A B$, this new scale, a straightforwardly reworded version of the ABS, does not seem to be suitable. While it had a clear factor structure and excellent reliability, it showed suboptimal validity in several respects. It failed to correlate with the ABS at all, correlated poorly with measures of motivation and engagement compared to the ABS, and correlated better than it should have done with academic performance. In general, teacher estimates of internal psychological states in students are moderate at best (Zhu \& Urhahnes, 2014), demonstrating how difficult it can be for teachers to make accurate inferences. The pattern of correlations here suggested that buoyancyindicating behaviours, at least as described in the TABS, may not be apparent to teachers, who instead relied on more salient information to evaluate students.

\section{ORCID}

Diarmuid Verrier (D) https://orcid.org/0000-0002-4148-3948
Lisa Reidy (D) https://orcid.org/0000-0001-5442-2346 


\section{REFERENCES}

Åhslund, I., \& Boström, L. (2018). Teachers' perceptions of gender differences: What about boys and girls in the classroom? International Journal of Learning, Teaching and Educational Research, 17(4), 28-44.

Bennett, R., Gottesman, R., Rock, D., Cerullo, F., \& Levin, Joel R. (1993). Influence of behavior perceptions and gender on teachers' judgments of students' academic skill. Journal of Educational Psychology, 85(2), 347-356.

Bernard, H. R., Killworth, P., Kronenfeld, D., \& Sailor, L. (1984). The problem of informant accuracy: The validity of retrospective data. Annual Review of Anthropology, 13, 495517.

Collie, R. J., Martin, A. J., Malmberg, L.E., Hall, J., \& Ginns, P. (2015). Academic buoyancy, student's achievement, and the linking role of control: A cross-lagged analysis of high school students. British Journal of Educational Psychology, 85(1), 113-130.

Drapeau, S., Saint-Jacques, M., Lépine, R., Bégin, G., \& Bernard, M. (2007). Processes that contribute to resilience among youth in foster care. Journal of Adolescence, 30, 449-466. DOI: 10.1016/j.adolescence.2007.01.005

Fan, X., Miller, B.C., Park, K., Winward, B.W., Christensen, M., Grotevant, H.D., \& Tai, R.H. (2006). An exploratory study about inaccuracy and invalidity in adolescent self-reporting surveys. Field Methods, 18, 223-244. DOI: 10.1177/152822X06289161

Funder, D. (2012). Accurate personality judgment. Current Directions in Psychological Science, 21(3), 177-182.

Howard, S., \& Johnson, B. (2000). What makes the difference? Children and teachers talk about resilient outcomes for children 'at risk'. Educational Studies, 26, 321-337. DOI:10.1080/03055690050137132

Hu, L., \& Bentler, P. (1999). Cutoff criteria for fit indexes in covariance structure analysis: Conventional criteria versus new alternatives. Structural Equation Modeling: A Multidisciplinary Journal, 6(1), 1-55.

jamovi project (2018). jamovi (Version 0.9) [Computer Software]. Retrieved from https://www.jamovi.org

Malmberg, L. E., Hall, J., \& Martin, A. J. (2013). Academic buoyancy in secondary school: Exploring patterns of convergence in English, mathematics, science, and physical education. Learning and Individual Differences, 23, 262-266. DOI: 10.1016/j.lindif.2012.07.014

Martin, A. (2002). Motivation and academic resilience: Developing a model for student enhancement. Australian Journal of Education, 46, 34-49. DOI: 10.1177/000494410204600104

Martin, A.J. (2007). Examining a multidimensional model of student motivation and engagement using a construct validity approach. British Journal of Educational Psychology, 77, 413-430. DOI:10.1348/000709906X118036

Martin, A.J. (2013). Academic buoyancy and academic resilience: Exploring 'everyday' and 'classic' resilience in the face of academic adversity. School Psychology International, 34, 488-499. DOI: 10.1177/0143034312472759

Martin, A.J. (2014a). Motivation and Engagement Scale - High School. Sydney, New South Wales, Australia: Lifelong Achievement Group.

Martin, A.J. (2014b). Academic buoyancy and academic outcomes: Towards a further understanding of students with attention deficit/hyperactivity disorder (ADHD), students without ADHD and academic buoyancy itself. British Journal of Educational Psychology, 84, 86-107 DOI: 10.1111/bjep.12007 
Martin, A.J., Colmar, S.H., Davey, L.A., \& Marsh, H.W. (2010). Longitudinal modelling of academic buoyancy and motivation: Do the '5Cs' hold up over time? British Journal of Educational Psychology, 80, 473-496. DOI:10.1348./000709910X486376

Martin, A.J. \& Marsh, H.W. (2006). Academic resilience and its psychological and educational correlates: A construct validity approach. Psychology in the Schools, 43, 267- 281. DOI: 10:1002/pits.20149.

Martin, A.J., \& Marsh, H.W. (2008a). Academic buoyancy: Towards an understanding of students' everyday academic resilience. Journal of School Psychology, 46, 53-83. DOI: 10.1016/j.jsp.2007.01.002

Martin, A.J., \& Marsh H.W. (2008b). Workplace and academic buoyancy: Psychometric assessment and construct validity amongst school personnel and students. Journal of Psychoeducational Assessment, 26, 168-184. DOI: 10.1177/0734282907313767

Meissel, K., Meyer, F., Yao, E. S., \& Rubie-Davies, C. M. (2017). Subjectivity of teacher judgments: Exploring student characteristics that influence teacher judgments of student ability. Teaching and Teacher Education, 65, 48-60.

Pas, E., \& Bradshaw, T. (2014). What affects teacher ratings of student behaviors? The potential influence of teachers' perceptions of the school environment and experiences. Prevention Science, 15(6), 940-950.

Putwain, D.W., \& Daly, A.L. (2013). Do clusters of test anxiety and academic buoyancy differentially predict academic performance? Learning and Individual Differences, 27, 157-162. DOI: 10.1016/j.lindif.2013.07.010

Renk, K., \& Phares, V. (2004). Cross-informant ratings of social competence in children and adolescents. Clinical Psychology Review, 24(2), 239-254.

Skinner, E. A., Kindermann, T. A., \& Furrer, C. J. (2008). A motivational perspective on engagement and disaffection: Conceptualization and assessment of children's behavioral and emotional participation in academic activities in the classroom. Educational and Psychological Measurement, 69, 493-525. DOI: 10.1177/0013164408323233

Martin, A. J. (2014). Academic buoyancy and academic outcomes: Towards a further understanding of students with attention-deficit/hyperactivity disorder (ADHD), students without ADHD, and academic buoyancy itself. British Journal of Educational Psychology, 84, 86-107. doi:10.1111/bjep.12007

Sudkamp, A., Kaiser, J., \& Moller, J. (2012). Accuracy of teachers' judgments of students' academic achievement: A Meta-Analysis. Journal of Educational Psychology, 104(3), 743-762.

Zhu, M., \& Urhahne, D. (2014). Assessing teachers' judgements of students' academic motivation and emotions across two rating methods. Educational Research and Evaluation, 20(5), 411-427. 